\title{
The Doctoral Challenge: Select Women Students' Experiences in a Higher Educational Leadership Doctoral Program
}

\author{
Vanessa Gonzales ${ }^{1}$, Markisha Venzant-Sampson ${ }^{1}$, Rachel Valle ${ }^{1} \&$ Anthony J. \\ Onwuegbuzie ${ }^{1, *}$ \\ ${ }^{1}$ Sam Houston State University, USA \\ *Corresponding author: Sam Houston State University, USA. E-mail: \\ tonyonwuegbuzie@aol.com
}

Received: May 27, 2015 Accepted: June 25, 2015 Published: September 15, 2015

doi:10.5296/ije.v7i3.7697 URL: http://dx.doi.org/10.5296/ije.v7i3.7697

\begin{abstract}
There is scant research on the topic of challenges and coping mechanisms necessary to the success of women doctoral students. Thus, the purpose of this study was to assess qualitatively the experiences of 3 women doctoral students enrolled at a 4-year university in southeast Texas in an attempt to explore the challenges that evolve while they are enrolled in a doctoral program. Specifically, we examined the lives of these women doctoral students outside of the program and their progression to the completion of their degrees. We attempted to provide insight surrounding the doctoral process, attrition, and completion. A collective case study research design was utilized in this study that was driven by a critical dialectical pluralistic philosophical stance (Onwuegbuzie \& Frels, 2013). Specifically, these 3 students were interviewed individually to examine their lived experiences as doctoral students. The verbal interview responses then were subjected to an ethnographic analysis (i.e., domain analysis, taxonomic analysis, componential analysis; Spradley, 1979), whereas their nonverbal responses were subjected to a classical content analysis. The ethnographic analysis of the verbal data revealed the following 2 themes: program perceptions and role inequity. The classical content analysis of the nonverbal data revealed 2 major categories that represented both explicit and inferred forms of communication: types of challenges and survival strategies. Implications of the findings are discussed.
\end{abstract}

Keywords: Women Doctoral Students, Doctoral Students, Critical Dialectical Pluralism, Collective Case Study, Higher Educational Leadership Doctoral Program 


\section{Doctoral Programs}

Doctoral programs have the lowest retention rates of the major degrees offered (i.e., bachelor's degrees, master's degrees, and doctoral degrees) (Gardner, 2009; Golde, 2005). Notwithstanding the exponential increase of doctoral programs in the United States, completion and graduation rates have not increased (Biegel, Hokenstad, Singer, \& Guo, 2006). Despite the many efforts of higher education institutions and faculty, graduation rates for doctoral programs remain significantly low (Golde, 2005). Disturbingly, doctoral student attrition rates in the United States have been measured at 57\% across all disciplines (Council of Graduate Schools 2008). Because of the alarming retention rates of doctoral programs, additional research is needed to determine why some students retain in a program versus drop out of the program.

Many researchers have examined causes of high attrition rates in doctoral programs; however, there is a lack of research regarding doctoral students' coping skills and adaptation practices (Gardner, 2009; Golde, 2005). Cooke, Sims, and Peyrefitte (1995) proposed that stress and lack of support from family and friends are to blame for the increase in graduate student dropout rates, whereas Gardner (2010) criticized the lack of socialization (i.e., the adoption of set values, skills, attitudes, norms, and knowledge affiliated with a specific entity) as a substantial influence. Furthermore, Iovacchini, Hall, and Hengstler (1985) suggested that some of the challenges encountered by graduate students involved crucial life characteristics, such as age, career stage, personal life circumstances, and finances. These obligations can deter doctoral students from completing their degrees.

\subsection{Doctoral Students and Attrition Rates}

Gardner (2009) interviewed 60 doctoral students and 34 faculty members in an effort to understand further what impact disciplinary and institutional cultures have on doctoral student attrition rates across six different disciplines within a single institution. This researcher discovered that faculty members were more likely to claim that a student was unprepared for graduate school and less likely to know why a student would drop out of the program. In contrast, Gardner (2009) found that students were more likely to blame the demands of the program and the lack of preparation of the students by the institution. In addition, the students were more likely to cite personal problems pertaining to children and marriage.

Similarly, Golde (2005) explored the role that disciplines and departments had on the attrition rates of doctoral students. This researcher collected data from 58 former doctoral students who dropped out of their programs before graduating. In addition, data were collected from case studies and observations of departments. Golde (2005) maintained that early attrition was better for all stakeholders versus late attrition. The researcher concluded that a large portion of attrition is avoidable. Also, departments that were flexible to changes and improvements had a lower attrition rate than did departments that were not flexible in changing their practices to benefit the students.

Ali and Kohun (2006) studied the high attrition rates of doctoral students in doctoral 
programs. These researchers studied the experiences that students had with isolation throughout the various stages of the doctoral programs. Ali and Kohun (2006) identified lack of communication, miscommunication, and confusion as reasons for students developing feelings of isolation. These researchers also identified countermeasures to combat feelings of isolation among doctoral students. Improved communication, stable socialization, and cohort model classes were among the recommendations proposed by Ali and Kohun (2006).

In contrast to the previous studies, Golde (1998) studied the attrition rates of first-year doctoral students who dropped out of their programs within that year. The researcher conducted four interviews to collect data for this study. Two of the interviews were attained from doctoral students in social science programs and the other two interviews were attained from doctoral students in natural science programs. Once the data were assessed, Golde (1998) determined that the students who dropped out did not regret leaving and mostly felt unprepared. The researcher identified measures that could be taken by administrators to ensure higher retention of doctoral students such as opportunities for students to engage with other students in various stages in the program and for students to observe professionals in the field.

\subsection{Doctoral Students and Persistence Rates}

Ivankova and Stick (2007) conducted a mixed methods research study to understand student persistence at the University of Nebraska Educational Leadership in Higher Education Doctoral program. The researchers collected 278 sets of survey responses and conducted four individual interviews (Ivankova \& Stick, 2007). The data collected by the researchers showed that students who had external support were more likely to graduate even if they had many external pressures from work and home. The majority of the students who completed the surveys identified self-motivation as a source of staying in the program. Ivankova and Stick (2007) documented that students depended on a solid infrastructure of resources available through the university.

In another study, Herzig (2002) conducted a qualitative research study via interviews with 10 faculty members and 18 graduate students who were directly involved in a mathematics doctoral program at a university. The interviews pertained to the perceived persistence and attrition rates of a sample directly involved with the department of mathematics. The data collected from the surveys revealed that the students were less likely to complete the program if they were not experiencing success in the program. The researcher believed that the immersed experience would further commit students to persist through the program.

Ulku-Steiner, Kurtz-Costes, and Kinlaw (2000) investigated whether women in gender-balanced or male-dominated programs were less likely to complete the program via the conduct of a mixed methods research study. These researchers hypothesized that women would have less support while in the program and that the presence of mentors would increase the persistence of women in the program. Ulku-Steiner et al. (2000) conducted the study over a 2-year period and discovered no statistically significant gender difference in terms of support. However, the presence of female faculty mentors increased persistence in women who remained in the program. 
Hoskins and Goldberg (2005) interviewed 33 doctoral students across 17 accredited counselor education programs in an effort to identify factors that contribute to the persistence of students who stayed in the program. The researchers found that persistence was more likely to occur when the faculty members and program administrators advised students on what to expect while in the program and what the demands of the program were. Hoskins and Goldberg (2005) also identified faculty and peer support and social and academic gatherings as ways to increase the likelihood of a doctoral student being retained in a program.

Church (2009) investigated why many doctoral students drop out shortly before the dissertation phase of their programs. The researcher tested the use of mock oral examinations and its relationship to increased retention. Church (2009) used interviews to collect data on doctoral students to determine whether a relationship existed. The researcher determined that students in programs where mock orals existed provided the students with the ability to cope better with the situation and the ability publicly and confidently to present research. Church (2009) recommended that future researchers include more studies on faculty mentoring programs because the programs studied often pertained to students working directly with faculty. The researcher indicated that students were further engaged in their doctoral programs as a result of working directly with faculty.

Additionally, Spaulding and Rockinson-Szapkiw (2012) conducted a qualitative research study to examine what factors contributed to the persistence of students in an educational doctoral program. After the data had been collected from 76 participants, the researchers identified common themes among the various participants. Among the various themes, Spaulding and Rockinson-Szapkiw (2012) found that students often felt lonely and stressed. Also, students expressed more comfort when they were socially integrated (i.e., cohorts, friendly advisors, supportive faculty and chairs).

Gardner (2010) studied the socialization of 60 doctoral students from six departments that varied from high completion rates to low completion rates. The researcher categorized the data into four themes: (a) support, (b) self-direction, (c) ambiguity, and (d) transition. Doctoral students expressed issues with becoming an independent researcher and simultaneously supporting peers. Also, students discussed fallacies in their orientation into the program as well as the preference of mentoring programs. Gardner (2009) suggested that the findings of this study be utilized to improve various aspects of doctoral programs, such as orientation and mentor programs.

\subsection{Doctoral Students and Graduation Rates}

Biegel et al. (2006) assessed 67 full-time and 52 part-time doctoral students enrolled in a social work doctoral program. The researchers recognized the need to improve graduation rates and conducted a survey to identify ways to improve the program. Once revisions to the program were made, Biegel et al. (2006) monitored the program for 10 years to determine whether the introduction of a re-vamped summer program would help increase graduation rates. After completing the study, the researchers determined that the summer program increased graduation rates for their program - particularly for part-time students. 
Schoot, Yerkes, Mouw, and Sonneveld (2013) researched factors that contributed to graduation delays for students in doctoral programs. The researchers surveyed students who had applied to defend their theses. Schoot et al. (2013) revealed that delays were more likely to occur when candidates experience practical setbacks, change their thesis plans, experience lack of communication from the department, and encounter extenuating personal circumstances. In addition, women experienced delays when they experienced changes in their marital statuses, whereas men experienced delays when they had a change in supervisor at work or had children.

Rodwell and Neumann (2008) examined doctoral students enrolled in various programs in Australia to determine what factors contributed to faster completion rates. The researchers utilized data from an annual survey to determine whether any statistical significance was present. Rodwell and Neumann (2008) concluded that international students who did not speak English at home and were enrolled in the hard sciences, law, or humanities programs, were more likely to graduate in less than 5 years. The researchers suggested using these results to implement further student support in an effort to attempt to increase completion rates among all students. Also, De Valero (2001) studied factors that affect the amount of time doctoral students have taken to complete their degree and completion rates. The researcher conducted a mixed methods research study that consisted of 1,438 graduate students enrolled in 57 programs at a single institution. De Valero (2001) found that student motivation and student ability were the two biggest factors associated with timely completion.

\subsection{Challenges and Coping Mechanisms of Doctoral Students}

Martinez, Ordu, Della Sala, and McFarlane (2013) investigated how students enrolled in a full-time doctoral program managed school, work, and life, in general. The researchers conducted five interviews with current full-time doctoral students who held graduate assistantships. Martinez et al. (2013) observed that students were not always successful with their time management skills and this was an important strategy for them to be effective in the program. The students discussed issues relating to all of the responsibilities of everything in their lives. Martinez et al. (2013) suggested that faculty members and program administrators strive to provide doctoral students with financial support, flexibility, and support.

Gold (2006) investigated the martial satisfaction of 65 graduate students, including both master's and doctoral students. The researcher interviewed 38 doctoral students and 27 master's students. Using the Marital Satisfaction Inventory-Revised, the researcher found that men and women experienced similar issues within their marriages while in the program. Gold (2006) identified that students experienced relationship conflict, frequent quarrels, and lack of resolution in differences. Also, the students experienced issues related to lack of communication, time spent together, and sexual fulfillment. The researcher also found that students often fought with their significant others regarding finances. Gold (2006) suggested that administrators consider providing support services for students in order to help with these possible issues. 
Schlemper (2011) studied the challenges with which graduate students often are faced, as well as the coping skills that they develop. Through the completion of a qualitative research study, the researcher conducted various focus groups with a total of 117 graduate students from 10 departments. Approximately $37 \%$ of the students interviewed were doctoral students. Schlemper (2011) identified time management, curriculum issues, and completing dissertations or theses as the top three challenges that graduate students encountered. Additionally, students identified the assistance and support of advisors, peers, and faculty members as their most effective coping strategy.

Moreover, Barnes and Randall (2012) employed data from the 2000 National Doctoral Program Survey to identify any differences that were present among the various academic disciplines. After quantitatively analyzing the data collected, the researchers discovered that students who were enrolled in a physical science or engineering program were more satisfied with the financial support and resources received from their programs than were students enrolled in other programs. Overall, Barnes and Randall (2012) learned that there were low satisfaction rates regarding post-graduation placement and orientation at the beginning of the program.

Using a mixed methods research approach, Combs and Onwuegbuzie (2012) examined doctoral students who were enrolled in a quantitative research methodology course, and analyzed their attitudes and coping strategies. To collect data for this study, the researchers conducted three focus groups with 18 doctoral students who had recently been enrolled in a quantitative research methodology course. Combs and Onwuegbuzie (2012) identified peer support, requests for help, and positive self-motivation as coping strategies practiced by students when enrolled in a quantitative research methodology course.

\subsection{Summary}

Several researchers have discussed issues pertaining to doctoral students' persistence and graduation rates (Biegel et al., 2006; Church, 2009; Gardner, 2010; Herzig, 2002; Hoskins \& Goldberg, 2005; Ivankova \& Stick, 2007; Rodwell \& Neumann, 2008; Schoot et al., 2013; Spaulding \& Rockinson-Szapkiw, 2012; Ulku-Steiner et al., 2000). In addition, researchers have studied doctoral students and how to improve attrition rates (Ali \& Kohun, 2006; Gardner, 2009; Golde, 1998, 2005). Similarly, other researchers have sought to identify the challenges and coping mechanisms of doctoral students as well (Barnes \& Randall, 2012; Combs \& Onwuegbuzie, 2012; Gold, 2006; Martinez et al., 2013; Schlemper, 2011). The literature reviewed by the researchers indicated that there is still research needed on the topic of challenges and coping mechanisms necessary to the success of women doctoral students. In addition, the prior research on this topic has yielded mixed results.

\subsection{Purpose Statement}

With this in mind, the purpose of this study was to assess qualitatively the experiences of three women doctoral students in an attempt to explore the challenges that evolve while they are enrolled in a doctoral program. Specifically, we examined the lives of these women doctoral students outside of the program and their progression to the completion of their 
degrees. We attempted to provide insight surrounding the doctoral process, attrition, and completion. The goal of this study was to obtain a better understanding about the complexities of each student's experiences throughout her participation in a doctoral program.

\subsection{Research Questions}

The research questions used to obtain data for this research study were: (a) What are the challenges encountered by select women students in their doctoral programs?; (b) How have these select women doctoral students reacted to these challenges?; (c) How have these experiences influenced the select women doctoral students' lives outside of their doctoral programs?; (d) What challenges do these select women doctoral students foresee in completing their doctoral programs?; and (e) How do select women doctoral students think that they will react to these future challenges? In accordance with Janesick (2004), the types of questions comprised basic descriptive, follow-up, experience/example, and comparison/contrast. These questions were formulated with the hope that the women doctoral students being interviewed would be able to give a vivid depiction of their lived experiences while in the program.

\subsection{Educational Significance}

There are many factors that contribute to the importance of this study. Attaining a doctoral degree can be very expensive for students. Once a doctoral student drops out of the program, the money that was already invested into the program is lost with no sign of the student ever recovering the funds invested (Ivankova \& Stick, 2007; Lovitts, 2001). Further, students who drop out of a doctoral program early also experience a loss of self-confidence, discouragement, and depression (Hoskins \& Goldberg, 2005; Lovitts, 2001).

Moreover, the United States always is in direct competition with other countries abundantly to produce educated citizens (Martinez et al., 2013). An increase in the graduation rates of students living in the United States who attain a doctoral degree allows for the United Stated States to remain globally competitive (Martinez et al., 2013). Lower doctoral graduation rates result in the United States losing highly trained specialists in a given field, which further dampens the education pool in the country (Hoskins \& Goldberg, 2005). Furthermore, high attrition rates contribute to the discouragement of faculty and the possibility of lost resources for the department (Ivankova \& Stick, 2007). Faculty discouragement and loss of resources can be detrimental to the progression of the department and can potentially tarnish the institution's reputation, resulting in the loss of potential future students and resources (Ivankova \& Stick, 2007). Thus, it is important to gain an understanding of why women students drop out of programs and to discover the necessary solutions to this problem. Also, it is relevant to know whether there are commonalities in the reasons that women students do not complete the programs.

\subsection{Philosophical Framework}

The research philosophical stance for our qualitative research study was what Onwuegbuzie and Frels (2013) recently referred to as a critical dialectical pluralistic stance, which is based on the assumption that social injustices occur at every segment of society-namely, at 
Bronfenbrenner's (1979) microsystem level (i.e., the immediate environment with which the participant closely interacts; e.g., home, religious institution), mesosystem level (i.e., the other systems in which the participant spends time; e.g., family, educational institution), exosystem level (i.e., the systems by which the participant might be influenced but of which he/she is not directly a member; e.g., the relationships among the participant's educators, other close family members), and macrosystem levels (i.e., the larger cultural world surrounding the participant; e.g., the society or community at large that includes societal belief systems, cultural norms, ideologies, laws, or policies that indirectly influence the participant).

According to Onwuegbuzie and Frels (2013), critical dialectical pluralist researchers adopt research-facilitator roles that empower the participant(s) to assume the role of participant-researcher(s), who, in turn, make research-based decisions at every stage of the research process, including at the stage of disseminating the findings, wherein they either present/perform the findings themselves or co/present/co-perform the findings with the research-facilitator(s). Our use of a critical dialectical pluralistic stance was particularly justified because, as surmised by Bowl (2003) and Wright (1997), women in education are an underrepresented and underserved group with respect to research attention.

\section{Method}

\subsection{Participants}

Participants were selected via a convenience sampling scheme wherein their selection was based on specific purposes to address the aforementioned research question questions (Onwuegbuzie \& Leech, 2007a). Specifically, the participants for this study, which included two of the researchers, were three women doctoral students at a 4-year university in southeast Texas with an enrollment of more than 19,000 students. These women each were enrolled in a an educational leadership doctoral program. As noted by Creswell (2002), three to five cases are sufficient for a case study research study. Also, Onwuegbuzie and Leech (2007a) stated that at least three participants per subgroup should be selected. Therefore, we deemed that our sample size was adequate for obtaining data saturation.

Two of the researchers, who also served as research participants, can be classified as being complete member participants (i.e., sharing in a common set of experiences, feelings, and goals; Adler \& Adler, 1987) because they were both researchers and participants in this study. Because all the interviewers and interviewees were doctoral students at the same institution, positive rapport already had been established among them prior to this study. As affirmed by Curry, Nembhard, and Bradley (2009), rapport is highly effective in the interview process because it motivates honesty between the interviewer and the interviewee, as well as minimizes fear or discomfort caused by unforeseen consequences that could emerge from shared information. Because three of the researchers were doctoral students and one of the researchers was a faculty member, as a team, they maintained both emic and etic perspectives-yielding what Onwuegbuzie (2012) referred to as an emtic viewpoint. 
Recognized by Pike (1967), an emic viewpoint is the description of data constructed by an insider - in this case, a doctoral student, whereas an etic viewpoint is constructed by someone outside the system or association or an outsider - in this case a non-doctoral student. Each interviewee was provided with a pseudonym.

2.1.1 Addison. The first participant was a White female who was 32 years of age. Addison was a married mother of two children under the age of 4 . Addison resigned from her full-time job as a psychology professor at a local community college in Texas to pursue her dream of earning her doctorate degree. She was a doctoral candidate enrolled in the educational leadership program with a focus in higher education administration at a public 4-year university in southeast Texas. In addition, she was in her fourth year and was serving as the co-instructor for a qualitative research methodology course that was taken by an earlier cohort.

2.1.2 Laura. The second participant was given the pseudonym, Laura. She was a single 27 year-old Hispanic female. Laura was a doctoral candidate enrolled in an educational leadership program at the same university as Addison. Having received a bachelor's degree in political science and a master's degree in public administration, Laura did not intend to enter the field of education initially. Her original plan was to enter federal politics. In 2005, Laura was employed part-time by a community college in southeast Texas. Laura expressed that in the years following, an interest in education, specifically higher education, began to develop. Currently employed full-time by the same community college, Laura's interest had intensified and she began pursuing her doctorate degree in higher education. She has continued to have an interest in politics and stated that she has the intentions of enrolling in law school after completion of her current doctoral program, with the hope of combining both studies and entering the field of higher education law.

2.1.3 Lucy. Lucy was a full-time professional working for a southeast Texas community college for approximately four years. Lucy was a female, 29 years of age, and had been married for 5 years. She was enrolled in her fourth semester as a doctoral student in an educational leadership program at the same university as Addison and Laura. Lucy was the program manager for two federally funded college preparatory programs, serving low-income and first-generation high school students. Along with academic strengthening activities, Lucy toured colleges and universities in the state of Texas, conducted skills workshops (e.g., time management, test anxiety), and provided intrusive advising to students in the program. Previously, Lucy worked at an alternative center for troubled youth. At the center, Lucy supervised the adolescents in their dormitories and conducted nightly focus groups. In addition, Lucy worked for various not-for-profit organizations, where she worked as a youth counselor and later a domestic violence counselor. Lucy's original plan was to be employed in social work, but she eventually became employed with her current job in higher education student success and felt the desire to move into the field of education. Lucy was originally from south Texas and moved to southeast Texas for college. She decided to remain in southeast Texas because she gained employment and was continuing graduate school nearby. 


\subsection{Instruments}

We conducted three semi-structured, one-on-one interviews to collect data for this study. The interview format used Kvale's (1996) criteria for creating a quality interview. Specifically, the questions were kept as short as possible with the hope that rich responses would ensue. Due to the highly individualized and relevant nature of the data instrument, the semi-structured, informal interview provided us with the opportunity to alter the questions based on the emerging information, as recognized by Patton (1990).

Table 1. Application of Guba and Lincoln's (1989) Authenticity Criteria to the Current Research

\begin{tabular}{|c|c|c|}
\hline $\begin{array}{l}\text { Authenticity } \\
\text { criterion }\end{array}$ & Definition & Application to Study \\
\hline Fairness & $\begin{array}{l}\text { All viewpoints are represented } \\
\text { even-handedly }\end{array}$ & $\begin{array}{l}\text { Each participant's responses were her } \\
\text { own and were accepted and recorded. }\end{array}$ \\
\hline $\begin{array}{l}\text { Ontological } \\
\text { authenticity }\end{array}$ & $\begin{array}{l}\text { Participants understand their } \\
\text { situation in more informed ways } \\
\text { as a result of participation in the } \\
\text { research }\end{array}$ & $\begin{array}{l}\text { The interview gave the participants an } \\
\text { opportunity to reflect on their } \\
\text { experiences in the program and to gain } \\
\text { understanding from those experiences. }\end{array}$ \\
\hline $\begin{array}{l}\text { Catalytic } \\
\text { authenticity }\end{array}$ & $\begin{array}{l}\text { Participants have a greater } \\
\text { insight into actions that they } \\
\text { might take to change their } \\
\text { situation as a result of } \\
\text { participation in the research }\end{array}$ & $\begin{array}{l}\text { In reflecting on their experiences via the } \\
\text { interview process, the participants were } \\
\text { able to see how their evolution in the } \\
\text { program had further developed since } \\
\text { entering the program and how they } \\
\text { continue to move and to evolve through } \\
\text { the program. }\end{array}$ \\
\hline $\begin{array}{l}\text { Educative } \\
\text { authenticity }\end{array}$ & $\begin{array}{l}\text { Participants understand the } \\
\text { situations of others in more } \\
\text { informed ways as a result of } \\
\text { participation in the research }\end{array}$ & $\begin{array}{l}\text { The interview process allowed the } \\
\text { participants to reflect on their } \\
\text { experiences in the doctoral program and } \\
\text { further made them aware of the } \\
\text { experiences of others in their cohort. }\end{array}$ \\
\hline $\begin{array}{l}\text { Tactical } \\
\text { authenticity }\end{array}$ & $\begin{array}{l}\text { Participants feel empowered and } \\
\text { enabled to act as a result of } \\
\text { participation in the research }\end{array}$ & $\begin{array}{l}\text { The participants were able to reflect on } \\
\text { their experiences and in having to } \\
\text { indemnify what helped them overcome } \\
\text { obstacles that they faced; their } \\
\text { preparedness and motivation increased. }\end{array}$ \\
\hline
\end{tabular}

The same five open-ended questions were used for each of the interviews. All eight members of the cohort and the two co-instructors developed the questions exactly 2 weeks prior to conducting the interviews. Creswell (2005) defined a qualitative interview as an exchange between a researcher and one or more participants, whereas the researcher asks general and open-ended questions and transcribes the data for analysis. A constructionist perspective (Roulston, 2010; Silverman, 2001) was used while the interviews were conducted and to 
evaluate the data collected. The format of the interview questions was a combination of basic descriptive, follow-up, and experience/example typologies (Janesick, 2004). Utilizing Guba and Lincoln's (1989) authenticity criteria (i.e., fairness, ontological authenticity, educative authenticity, catalytic authenticity, and tactical authenticity; cf. Table 1 for definitions), the interview questions were conclusively evaluated via debriefing interviews with each of the participants following the completion of their initial interviews to ensure legitimacy of the research. The results of the evaluations are illustrated in Table 1. The interview questions were: (a) Describe the challenges you have encountered so far in your doctoral program; (b) How have you reacted to these challenges?; (c) How have these experiences influenced your life outside your doctoral program?; (d) What challenges do you foresee in completing your doctoral program?; and (e) How do you think you will react to these future challenges?

\subsection{Procedure}

2.3.1 Data collection. Prior to the commencement of each of the interviews conducted with Addison, Laura, and Lucy, informed consent was obtained. Merriam (1998) stated, "any and all methods of gathering data can be used in a case study" (p. 28). Verbal and nonverbal data were collected by conducting the three individual one-on-one interviews. The observations that took place during the interviews would be classified as focused observations. Each participant gave her permission to be recorded during the interview. Furthermore, prior to the commencement of the interviews, each participant was explained the purpose of the study by the interviewer, in addition to the methods of data collection. There were no risks of harm identified.

2.3.2 Interviews 1 and 2. Both Lucy and Laura interviewed each other in a classroom. The classroom size was approximately 400 square feet with one lime green wall and three grey walls. The classroom was equipped with multiple grey tables and chairs, a single computer, and a large projector screen and white board located in the front of the room along the lime green wall. The flooring was grey and green laminate and the chairs had wheels at the bottom of them. There was a podium with a desk at the front of the classroom. The room was quiet, and provided no apparent distractions. At the beginning of the interview, the room was fully lighted. Almost halfway through the interviews, the motion-censored lights turned off due to the lack of movement within the classroom. The only noise in the room during the interview came from the chairs when the interviewer or Lucy would move in the chair.

The temperature of the room was mildly warm, and aside from Laura and Lucy, no one else was present. The smell of onion, cumin, and chili powder faintly resided due to the cup of chili that Lucy brought for dinner on the day the interview that was conducted. Laura and Lucy were sitting side by side; they turned to face each other by turning the chairs approximately one foot away from each other. Laura had her white Apple MacBook pro laptop in front of her, along with her notebook and other textbooks on the table beside her. Lucy's grey HP Elitebook laptop also was on the table in front of us facing Laura because Lucy was using the camera to video record the interview; however, because of technical difficulties, the footage was not saved. The audio recording was logged by use of a digital voice recorder. Lucy's interview of Laura was video recorded. Laura provided Lucy with 
clarification when requested and Laura asked follow-up questions when she wanted to explore possible themes relevant to the topic at hand. Laura's interview with Lucy lasted 23 minutes.

At the conclusion of Lucy's interview of Laura, Lucy explained to Laura that she would be transcribing the interview within 1 week and would send the transcription to her for her review. The audio recording was relocated onto her encrypted, password-protected laptop to ensure confidentiality. Confidentiality provided both an intrinsic and instrumental value to the research because it demonstrated respect and protection of Laura's disclosed information (Easter, Davis, \& Henderson, 2004). The 18-page transcription was completed within 6 days of the interview and an electronic copy was provided to Laura via electronic mail. A copy of the transcript was provided to Laura in order to give her the opportunity to member check the transcription for accuracy and adequacy (Krefting, 1991). Member checking allows the participant to review the information and to confirm that the data collected are correct and that the data collected reflect adequacy (Manning, 1997). Once any requested changes are made, the member approves the data; thereby authenticating the collected data (Manning, 1997). Within 2 days, Laura reviewed the transcription and expressed that the transcription was accurate and needed no corrections or additions.

Laura transcribed her interview of Lucy within 72 hours of when the interview occurred and sent the transcription to Lucy via email to member check the data collected from the interview. Upon review of the data, Lucy requested that a few changes be made to the data collected. Lucy approved the data once her requested changes were made. Regarding some of Lucy's changes, she felt uncomfortable having some of her comments in the transcription and requested that they be removed from the transcript. Laura reminded her that she would change anything she requested and that everything was confidential.

2.3.3 Interview 3. In order to collect the data, the interview took place in a faculty computer laboratory on the third floor of the satellite campus where the course was held. Based on our initial observations, the room appeared to be vacant and not in use. The laboratory did not have any windows and the walls were painted white. Each of the walls had computer desk desks that ran along the perimeter of the walls. Each desk had a computer on it; there were approximately 15 computers in the laboratory. The only people in attendance were Addison and the researcher. In addition, the computer laboratory was quiet and free from distractions and interruptions. There was no noticeable scent in the room and the temperature was comfortable. With Addison's permission, the researcher wrote notes about visual observations, in addition to recording the audio. Audio was recorded with both a portable voice recorder and the voice recorder from the researcher's cell phone. Along with the scripted questions, two follow-up questions were asked. These follow up questions were: (a) When you entered the program were you working? and (b) What has been one of the things that your husband has done or said that has been the biggest thing that pushes you? The duration of the interview was 27 minutes and 12 seconds. Transcription of the data took place over the 3 days following the interview. Transcription of the data collected from the interview was sent via email to Addison for member checking (Manning, 1997). The member-checked transcription was returned to the researcher within 3 days of forwarding it 
to Addison. She suggested that we include more descriptors to add more depth to the responses, as well as to think of the transcription as more of a movie script. Approval was obtained from Addison and the analyses took place shortly thereafter.

\subsection{Debriefing Interviews}

Debriefing interviews conducted on each interviewer were used to generate an external assessment and to develop reflexivity on the part of the interviewer regarding what occurred during the study (Onwuegbuzie, Leech, \& Collins, 2008). The debriefing interviews took place via cell phones and via Skype. Skype was used to record any nonverbal communication that occurred during the interviews. Questions asked during the debriefing interviews addressed Guba and Lincoln's (1989) authenticity criteria. The interviewers and their peers were in their own places of residence during the debriefing interviews, which lasted 10 minutes. Specifically, the four debriefing questions asked of Laura were: (a) How comfortable were you interacting with your participant?; (b) What findings surprised you?; (c) To what degree do you think the setting impacted the dynamics of the interview(s)?; and (d) In what ways, if any, do you feel you are a different person now that you have conducted the interview(s)? The four debriefing questions asked of Lucy were: (a) How comfortable were you interacting with Laura?; (b) To what degree were the findings similar or dissimilar to your thoughts prior to conducting the interview?; (c) Were there any findings that came out of the interview that may have surprised you?; and (d) In the future, how will you conduct interviews based on what you learned during the interview with Laura? Finally, the four debriefing questions asked of Addison were: (a) How would you describe your experience with the interview with your participant?; (b) To what degree do you think the setting impacted the dynamics of the interview?; (c) In the future, how will you conduct interviews based on what you learned during the interview?; and (d) At any point during the interview did the participant share something with you or did you share something with her that you were not expecting and if so how did you respond? The format of the debriefing interviews was similar to the initial interviews with Laura, Lucy, and Addison in that they were informal and semi-structured. Once the debriefing interviews had been completed and transcribed, the data analysis commenced.

\subsection{Research Design}

A collective case study design was utilized for the research in this study (Stake, 2005; Yin, 2004). Stake (2005) stated, in collective case studies, cases are chosen because the researcher believes that understanding them would lead to better understanding, or even better theorizing, about a still larger collection of cases. In the present inquiry, understanding the participants' experiences and perceptions as they progressed through the doctoral process was the crux.

\subsection{Verification}

After implementing member-checking interviews, copies of the transcriptions of the interviews were electronically sent to each participant for her review. To ensure that "contextuality, multivocality, and plausibility of fairness" (Manning, 1997, p. 101) was 
considered, member-checking was performed to guarantee an accurate and adequate depiction of the responses. As noted by Manning (1997), this procedure is critical for gathering insights of participants. This indicated that the researchers were not the sole originator of the research findings and instead co-constructors.

\subsection{Legitimation}

2.7.1 Threats to internal credibility. Internal credibility is concerned with the perceptions and outcomes caused by a research study's data (Onwuegbuzie \& Leech, 2007b). As identified by Onwuegbuzie and Leech (2007b), 14 possible threats to internal credibility exist. Five of these threats (i.e. descriptive validity, reactivity, researcher bias, confirmation bias, and voluptuous legitimation) were present in this research. Each threat is discussed below.

2.7.2 Descriptive validity. Maxwell (1992) noted that descriptive validity refers to the accuracy of a documented interview from its original source. Various practices were implemented to ensure that descriptive validity was maximized. Audio recordings of the interview were obtained and transcriptions of the interview, including notes about both verbal and nonverbal forms of communication, were completed. The transcriptions then were sent electronically to Addison, Laura, and Lucy (i.e., member-checking) to provide each of them the opportunity to edit or to clarify any misinterpretations. Analysis of the data did not commence until these assurances were completed.

2.7.3 Reactivity. Reactivity is concerned with whether results are influenced by some level of threat to the participant (Onwuegbuzie \& Leech, 2007b). Before beginning the interviews, each participant was assured that her true identity would be concealed. Addison, Laura, and Lucy are the pseudonyms for the participants and, therefore, provided further assurance that confidentiality would be kept. Furthermore, we ensured each participant that any information that she disclosed would not pose any level of threat or retribution. This lowered reactivity and allowed the participants to respond to questions naturally.

2.7.4 Researcher bias. Onwuegbuzie (2003) cautioned that researcher bias could impact a participant's responses, behaviors, or actions in a way that is more favorable toward the intended goals of the research. To reduce this bias, another member of the research team conducted a debriefing interview so that each of the participants could reflect on the data and attempt to eliminate bias (Onwuegbuzie et al., 2008).

2.7.5 Confirmation bias. Confirmation bias refers to researchers' assumptions about the results of a particular study prior to conducting the analysis (Onwuegbuzie, 2003). Because Addison, Laura, and Lucy were enrolled in the same doctoral program, imposing our personal perceptions on the analysis of this study would be recognized as confirmation bias. To eliminate this threat, we subdued any preconceived notions about possible emerging categories or responses that were disclosed. These factors did not reveal themselves until the analyses of data were completed.

2.7.6 Voluptuous Legitimation. Voluptuous legitimation refers to the researcher's knowledge base surrounding the acquired data (Onwuegbuzie \& Leech, 2007b). Because we were enrolled in a qualitative research methodology course, we attained the knowledge and 
training techniques needed to complete a qualitative research study effectively. In addition, the two co-instructors of the qualitative research methodology course that we took provided us with supervision and guidance as the research study progressed, resulting in modifications to the analysis of this study. Lastly, the debriefing interview also helped us remain reflexive and effectual.

2.7.7 Interpretive validity. The extent to which a researcher's interpretation of an account can influence and assign meaning to data is identified as interpretive validity (Maxwell, 1992). Additionally, interpretive validity entailed the ability of the researcher to refrain from impeding his/her own bias onto the findings. This form of validity encompassed an emic perspective (i.e., description of data constructed by an insider; Pike, 1967). Ensuring that the findings were exclusively grounded in each of the participant's perspectives, only direct quotations were evaluated to ensure that the researchers' own viewpoints did not affect the results.

\subsection{Analysis}

An ethnographic analysis (Spradley, 1979), consisting of a domain analysis, taxonomic analysis, and componential analysis, was exercised to evaluate the verbal data in this study. To analyze the nonverbal data presented in this collective case analysis, a classical content analysis was performed. As suggested by Leech and Onwuegbuzie (2007), utilizing multiple forms of analyses to evaluate research findings can strengthen the cogency and credibility of a study. Qualitative analysis software QDA Miner Version 4.0.3 (Provalis Research, 2011) was operated to perform the domain analysis, taxonomic analysis, componential analysis, and classical content analysis. QDA Miner was used for coding, annotating, collecting, and examining the data (Provalis Research, 2011).

The practice of an ethnographic analysis is performed to generate cultural meaning from a group of people's dialogue, experiences, and environments with a goal of finding a connection among the three parts (Spradley, 1979). Leech and Onwuegbuzie (2008) stated that "It is the examination of these parts that helps the researcher to understand the overall culture of the informant" (p. 595). Domain analysis, followed by taxonomic analysis, componential analysis, and classical content analysis, are discussed.

Domain analysis refers to the creation of cultural meaning by the usage of symbols (Spradley, 1979). Symbols, in this context, refer to any object or event that represents something (Spradley, 1979). Spradley (1979) identified three features that all symbols require: (a) the symbol itself, (b) what the element is that the symbol refers to, and (c) the relationship between the symbol and the element to which the symbol refers. To obtain a comprehensive understanding of the symbols identified by Addison, Laura, and Lucy, semantics were investigated to ascertain what relationships existed between the symbols and the elements to which the symbols referred. Spradley (1979) also recognized nine commonly used semantic relationships. These relationships are: (a) strict inclusion (i.e., $\mathrm{X}$ is a kind of $\mathrm{Y}$ ); (b) spatial (i.e., $\mathrm{X}$ is a place in $\mathrm{Y} / \mathrm{X}$ is part of $\mathrm{Y}$ ); (c) cause-effect (i.e., $\mathrm{X}$ is a result of $\mathrm{Y} / \mathrm{X}$ is a cause of $\mathrm{Y}$ ); (d) rationale (i.e., $\mathrm{X}$ is a reason for doing $\mathrm{Y}$ ); (e) location for action (i.e., $\mathrm{X}$ is a place for doing $\mathrm{Y}$ ); (f) function (i.e., $\mathrm{X}$ is used for $\mathrm{Y}$ ); (g) means-ends (i.e., $\mathrm{X}$ is a way to do $\mathrm{Y}$ ); (h) 
sequence (i.e., $\mathrm{X}$ is a step or stage in $\mathrm{Y}$ ); and (i) attribution (i.e., $\mathrm{X}$ is an attribute, or characteristic of $\mathrm{Y})$.

A six-step procedure presented by Spradley (1979) was exercised in order to complete the domain analysis. These steps involved: (a) the selection of a single semantic relationship, (b) preparation of an analysis worksheet, (c) selection of sample statements from the informant, (d) search for cover terms and included terms that coincide with the semantic relationship, and (e) formulation of structural questions for the domain. Each of these five steps was repeated to analyze each domain. Although Step 6, the (f) construction of a list of hypothesized domains, was not to be completed in this study, the results obtained by Steps 1 through 5 provided a better understanding about the usage of symbols as they relate to Addison's, Laura's, and Lucy's experiences in a doctoral program.

Expanding on the domain analysis, a taxonomic analysis consists of using the identified domains and creating a taxonomy, which is defined as a classification system that inventories and classifies the domains to discover the relationships among the domains (Spradley, 1979). An eight-step procedure is necessary in the completion of a taxonomic analysis. According to Spradley (1979), the procedure comprises: (a) selection of a domain for taxonomic analysis; (b) identification of the appropriate substitution frame for analysis; (c) search for possible subsets among the included terms; (d) search for larger, more inclusive domains that might include the subset being analyzed; (e) construction of a tentative taxonomy; (f) formulation of structural questions to verify taxonomic relationships; $(\mathrm{g})$ creation of additional structural interviews; and (h) construction of a completed taxonomy. The final two steps of this analysis were not completed; however, results from Steps 1 through 6 were obtained.

A componential analysis refers to the discovery of attributes (i.e., elements of information) and their association with cultural symbols (Spradley, 1979). Spradley (1979) suggested the usage of componential analysis be exercised to produce a more comprehensive understanding of the informant's reality. To complete this analysis, eight steps should be completed (Spradley, 1979). These steps are: (a) selection of a contrast set for analysis, (b) completion of an inventory of all contrasts previously discovered, (c) preparation of a paradigm worksheet, (d) identification of dimensions of contrast that have dual values, (e) combination of closely related dimensions of contrast into dimensions that have multiple values, (f) preparation of contrasting questions to elicit missing attributes and new dimensions of contrast, (g) completion of an interview to elicit needed data, and (h) preparation of a completed paradigm.

Lastly, a classical content analysis of Addison's, Laura's, and Lucy's nonverbal data was completed. Holsti (1969) defined content analysis as "any technique for making inferences by objectively and systematically identifying specified characteristics of messages" (p. 14). This method of analysis involved the creation of categories, usage of codes associated with each category, and the level of frequency in which the codes appear. Researchers have defined coding as the process of classifying and labeling units of data (Glaser \& Strauss, 1967; Lincoln \& Guba, 1985; Miles \& Huberman, 1994).

Category development is a critical component of classical content analysis. Categories are 
identified as clusters of related and linked data (Hsieh \& Shannon, 2005). According to Constas (1992), the creation of categories should include components of (a) origination, (b) verification, and (c) nomination. The construction of categories can originate from research participants, programmatic language, the investigation itself, review of literature, or interpretations of the data (Constas, 1992). In this research, category development emerged from each research participant, Lucy, Laura, and Addison. To verify the categories discovered, a review of related literature was completed to confirm the current findings with those of past research. Lastly, concerned with naming the emergent categories, the identification of each category was created based on the participants' nonverbal forms of communication. An a posteriori approach was recognized because the categories were not constructed until after the data were analyzed (Constas, 1992).

Onwuegbuzie and Byers (2014) argued that most researchers exclusively focus on verbal communication; often overlooking critical nonverbal cues that play an equal, if not more significant, role in the qualitative data analysis. As a result, Addison's, Laura's, and Lucy's nonverbal communication was examined. Aiding in this examination was Gorden's (1980) typology of nonverbal communication. This typology contains four nonverbal elements referred to as: (a) kinesics (i.e., behaviors characterized by body language and posture), (b) proxemics (i.e., behaviors indicating an established relationship between the interviewee and interviewer), (c) chronemics (i.e., long pauses and moments of silence and/or hesitations), and (d) paralinguistics (i.e., behaviors associated with vocal expression characteristics).

\section{Results}

\subsection{Domain Analysis}

Beginning the execution the domain analysis (Spradley, 1979), an examination of Addison's, Lucy's, and Laura's transcriptions was completed. Cover terms and included terms, referencing the identified semantic relationships, were identified to prepare a domain analysis worksheet. Strict inclusion (i.e., X is a kind of Y) (Spradley, 1979) was the most suitable semantic relationship between the identified cover terms and included terms derived from the participants' transcriptions. Structural questions for possible domains then were created in order to assist in the classification of each domain. Two domains (i.e., program perceptions and role inequity) were identified, namely: program perceptions and role inequity.

3.1.1 Program perceptions. The data revealed a very notable relationship between each participant and her membership in the doctoral program. Addison, Laura, and Lucy each discussed the significance that the doctoral program played in each of their lives, as well as the sacrifices that each of them had had to make in order to maintain her membership in the doctoral program. Interestingly, Addison, Laura, and Lucy each vividly described the challenges and difficulties encountered as a result of being a doctoral student. Included terms such as "challenging," "overwhelming," and "beneficial" were discovered in all the transcriptions. However, Addison, Laura, and Lucy also expressed a desirable connection to the program despite the hardships. An excerpt from Lucy's transcription provides an example 
of this acknowledgement of challenge, yet dedication to remaining a doctoral student:

I've noticed that when my workload is rough, school is going to be just as rough if not even more so. One of the things I knew going into the program was that I wanted to get my doctorate degree.

Another example, extracted from Addison's transcript. is as follows:

I have got three papers out for publication right now and one has been accepted with revisions; one has been accepted and one we are waiting to hear on. It's wonderful...it's filling up my vita. I love the experience. However, I need to do my proposal. That is what is going to get me my degree.

Laura also expressed a statement describing the connection that she valued from being a graduate student, regardless of the multiple challenges. In her interview, one of the researchers asked Laura about how she thinks she would feel when she had completed her doctoral program. Laura replied:

For me, speaking from personal experience with my other two degrees, I always have this postpartum thing happen to me where I, I go home and I'm like I don't have anything to do... like, this is so awkward. I miss it [school].

The contrasting perspectives depicted in the research study directed the formulation of the three structural questions. These questions were: (a) Are the dual perceptions (i.e., challenging and rewarding), stemming from the participants' membership in the doctoral program, equally balanced?; (b) How does each participant manage their dual perceptions?; (c) Does this dual perception affect other areas of the participants' lives? Although a follow-up interview has not been conducted, these questions would serve as an effective tool for further exploration of this symbolic domain.

3.1.2 Role inequity. Addison, Laura, and Lucy each expressed the varying roles present in her lives. Lucy identified the following roles in her life: (a) doctoral student, (b) wife, (c) career professional, and (d) motivator. Laura identified the following roles in her life: (a) doctoral student, (b) career professional, and (c) friend. Addison identified the following roles: (a) doctoral student, (b) wife, and (c) mother. Although the roles were not identical among the participants, a struggle to maintain balance in their identified roles was expressed by all. For this domain, the identified roles served as the included terms.

A quotation from Lucy's transcription depicting her struggle to maintain balance between among the multiple roles in her life was discovered when the researcher asked Lucy about her family life. The quotation expressed:

And then, of course, my husband he's a big family person. I mean he was ready [for children] from Day 1. It's just not, I don't know. It's just a weird. It's a weird thing. It's a weird thing for me having to envision myself as a mother, much less being in a doctoral program and then being a mother.

A struggle between being a career professional, a doctoral student, and a friend was 
expressed in the following excerpt extracted from Laura's transcription:

When I'm not here [in class], I'm at work until 8 or 9 o'clock at night anyways so, and I prefer that so I'm not complaining but, when your there all the time, when do you, when do you do stuff outside of work and outside of school? You know? So, I definitely would say my personal life has suffered drastically throughout all of this. Like my friends...I see them maybe once in May and once in December because that's when we don't have school.

Addison, the only participant who identified with the role of mother, vividly described her imbalance between her doctoral student role and mother role in the following passage:

That is what my life is right now. My life is dissertation and potty. That is what I do with all my days. It has really influenced me because I worry that I did not cherish that time with my son like I wanted to because I was caught up in working on my doctorate.

Because of the inequity present among the identified roles of the participants, three structural questions were constructed. They were: (a) What identified role is the most dominant in each participants' life? Which role is the least dominant?; (b) What strategies do the participants exercise to manage the varying roles?; and (c) How do the identified roles intertwine? Although the participants' transcribed data were insightful, clarity on the identified structural questions can provide a more inclusive understanding about each participant's life.

\subsection{Taxonomic Analysis}

A classification system, based on Addison's, Laura's, Lucy's identified domains was created to perform the taxonomic analysis (Spradley, 1979). As expressed in Spradley's (1979) eight-step procedure for completing a taxonomic analysis, each domain extracted from the domain analysis was examined. Appropriate substitutions frames for the included terms were recognized. Then, a tentative taxonomy and set of structural questions were completed. Because the structural questions were not presented to the participants, completed taxonomies were unable to be finalized. However, Steps 1 through 6 of Spradley's (1979) eight-step procedure are detailed below for each domain.

3.2.1 Program perceptions. Studying the dual perceptions detailed in the domain analysis revealed the included terms (i.e., "challenging," "overwhelmed," and "beneficial") necessary for the taxonomic analysis of this domain. The substitution frame adopted was "describes." For example, challenging describes the doctoral program. These frames were able to be subdivided into two classifications of perceptions: (a) optimistic perceptions and (b) pessimistic perceptions.

Two structural questions were constructed to execute the taxonomic analysis. These questions were: (a) What value has enrollment in the doctoral program added to each participants' life? What detriments have resulted?; and (b) What other descriptors could be used to identify each participants' experience in the doctoral program? These questions were unable to be presented to Addison, Laura, and Lucy, because of the timeframe in which this study was 
completed.

3.2.2 Role inequity. As noted previously, the identified roles associated with Addison, Laura, and Lucy served as the included terms recognized in the domain analysis. The substitution frame for the included terms was "is a kind of" role. For example, being a doctoral student is a kind of role for Addison, Laura, and Lucy. As previously mentioned, although roles varied among the participants, the identified roles can be further subdivided into the following three roles: (a) scholar roles (e.g., doctoral student), (b) personal roles (e.g., wife, friend, or mother), and (c) occupational roles (e.g., career professional).

As a result of the taxonomy, two structural questions were constructed to enable the researcher to explore further the culture of the participants; however, the questions were not presented to the participants. The questions were: (a) To what extent does the challenge of finding balance among each participants' roles affect their everyday lives?, and (b) What strategies for finding equity among the identified roles have been advantageous? Which have been disadvantageous? Based on the inability to obtain responses to these structural questions, a completed taxonomy was unable to be produced.

\subsection{Componential Analysis}

At the conclusion of the taxonomic analysis, a componential analysis was initiated. A search for contrasts among the participants' experiences in the doctoral program was completed. Then, these contrasts were clustered and uniquely categorized based on the connections shared. Based on the findings of the domain and taxonomic analyses, contrasts about role identification and program perceptions existed among the three participants.

A paradigm worksheet followed the examination of the contrasts. Identification of the dimensions of contrast that had dual values and the combination of closely related dimensions of contrast into ones that had multiple values was completed. To investigate further the identified dimensions, contrasting questions were generated to help differentiate the contrasting perceptions of the doctoral program and competing roles held by Addison, Laura, and Lucy. These questions were: (a) Are the dual values associated with program perceptions and role inequity serving as methods of control over each participants' life?, (b) Does the contrasting perceptions about the program and role inequity affect the participants' probability of completing their doctoral degree?, and (c) Can balance among the contrasting perceptions of the program and role inequity be attained? These questions, not presented to the participants, were designed so that a "yes" or "no" response could be provided with the goal of identifying ways of representing added information about the semantic relationships that the taxonomic analysis was incapable of managing.

\subsection{Classical Content Analysis}

A classical content analysis using Gorden's (1980) typology of nonverbal communication additionally was used to evaluate Addison's, Laura's, and Lucy's nonverbal modes of communication. Addison, Laura, and Lucy each exhibited multiple displays of nonverbal cues. Nonverbal cues for Addison, Laura, and Lucy are displayed in Tables 2, 3, and 4, respectively. Calculating the frequencies, Lucy, Laura, and Addison displayed 48, 79, and 57 
instances of nonverbal cues, respectively.

Table 2. Classical Content Analysis of Lucy's Nonverbal Cues using Gorden's (1980) Typology Classification

\begin{tabular}{lcll}
\hline Nonverbal Cue & Frequency & Potential Codes & Typology \\
\hline Head Nods & 9 & Adapting to Surroundings & Kinesics \\
Opened Eyes Widely & 4 & Time/Procrastination & Kinesics \\
Rolled Eyes & 10 & Mental Exhaustion/ Stress & Kinesics \\
Took Deep Breath & 2 & Finding Balance & Chronemics \\
Subtle Hand Movement & 6 & Mental Exhaustion/ Stress & Kinesics \\
Squinted Eyes & 2 & Mental Exhaustion/ Stress & Kinesics \\
Waved Hands & 7 & Mental Exhaustion/ Stress & Kinesics \\
Giggled & 3 & Positive Outlook & Paralinguistics \\
Crossed Arms & 1 & Mental Exhaustion/ Stress & Proxemics \\
Shifting Seating Positions & 1 & Mental Exhaustion/ Stress & Proxemics \\
Paused & 1 & Finding Balance & Chronemics \\
Shifted Vocal Tone & 1 & Mental Exhaustion/ Stress & Paralinguistics \\
Shifted Volume & 1 & Fear of Failure & Paralinguistics \\
\hline
\end{tabular}

Note. Classical Content Analysis was formulated using QDA Miner Version 4.0.3 (Provalis Research, 2011), a qualitative software program. Codes were produced by the researchers, a priori. Typologies were created by Gorden (1980).

Table 3. Classical Content Analysis of Laura's Nonverbal Cues using Gorden's (1980) Typology Classification

\begin{tabular}{lcll}
\hline Nonverbal Cue & Frequency & Potential Codes & Typology \\
\hline Head Nods & 11 & Adapting to Surroundings & Kinesics \\
Opened Eyes Widely & 6 & Time/Procrastination & Kinesics \\
Rolled Eyes & 9 & Mental Exhaustion/ Stress & Kinesics \\
Took Deep Breath & 5 & Finding Balance & Chronemics \\
Subtle Hand Movement & 4 & Mental Exhaustion/ Stress & Kinesics \\
Squinted Eyes & 6 & Mental Exhaustion/ Stress & Kinesics \\
Waved Hands & 12 & Mental Exhaustion/ Stress & Kinesics \\
Giggled & 4 & Positive Outlook & Paralinguistics \\
Crossed Arms & 3 & Mental Exhaustion/ Stress & Proxemics \\
Shifting Seating Positions & 4 & Mental Exhaustion/ Stress & Proxemics \\
Paused & 5 & Finding Balance & Chronemics \\
Shifted Vocal Tone & 7 & Mental Exhaustion/ Stress & Paralinguistics \\
Shifted Volume & 3 & Fear of Failure & Paralinguistics \\
\hline
\end{tabular}

Note. Classical Content Analysis was formulated using QDA Miner Version 4.0.3 (Provalis Research, 2011), a qualitative software program. Codes were produced by the researchers, a 
priori. Typologies were created by Gorden (1980).

Table 4. Classical Content Analysis of Addison's Nonverbal Cues using Gorden's (1980) Typology Classification

\begin{tabular}{lcll}
\hline Nonverbal Cue & Frequency & Potential Codes & Typology \\
\hline Head Nods & 8 & Adapting to Surroundings & Kinesics \\
Opened Eyes Widely & 6 & Time/Procrastination & Kinesics \\
Rolled Eyes & 4 & Mental Exhaustion/ Stress & Kinesics \\
Took Deep Breath & 1 & Finding Balance & Chronemics \\
Subtle Hand Movement & 11 & Mental Exhaustion/ Stress & Kinesics \\
Squinted Eyes & 8 & Mental Exhaustion/ Stress & Kinesics \\
Waved Hands & 6 & Mental Exhaustion/ Stress & Kinesics \\
Giggled & 3 & Positive Outlook & Paralinguistics \\
Crossed Arms & 2 & Mental Exhaustion/ Stress & Proxemics \\
Shifting Seating Positions & 1 & Mental Exhaustion/ Stress & Proxemics \\
Paused & 3 & Finding Balance & Chronemics \\
Shifted Vocal Tone & 3 & Mental Exhaustion/ Stress & Paralinguistics \\
Shifted Volume & 1 & Fear of Failure & Paralinguistics \\
\hline
\end{tabular}

Note. Classical Content Analysis was formulated using QDA Miner Version 4.0.3 (Provalis Research, 2011), a qualitative software program. Codes were produced by the researchers, a priori. Typologies were created by Gorden (1980).

After the nonverbal data documented in the transcriptions were identified, two major categories emerged. These categories represented both explicit and inferred forms of communication (Hsieh \& Shannon, 2005). They were: (a) types of challenges and (b) survival strategies. Each category contained three different codes used to classify Laura's transcription (Glaser \& Strauss, 1967; Lincoln \& Guba, 1985; Miles \& Huberman, 1994). The codes relating to the types of challenges were: (a) fear of failure, (b) time/procrastination, and (c) mental exhaustion/stress. Associated with the survival strategies category were: (a) finding balance, (b) positive outlook, and (c) adapting to surrounding.

Examples of Gorden's (1980) paralinguistics were displayed in each participants' nonverbal data by the recognition of giggling, shifts in vocal tone, and shifts in volume. Lucy's paralinguistics accounted for five out of 48 identified nonverbal cue occurrences. Laura's paralinguistics accounted for 14 out of 79 identified nonverbal cue occurrences and Addison's paralinguistics accounted for seven out of 57 identified nonverbal cue occurrences.

Appearing minimally were the participants' chronemic and proxemic forms of nonverbal communication. Chronemics were noticeable in this research study by use of Addison's, Laura's, and Lucy's pauses and deep breaths. These nonverbal cues, categorized under "finding balance," were presented when the participants discussed their challenges with managing school, work, and personal life expectations. This nonverbal element accounted for four out of 57, 10 out of the 79, and three out 48 identified nonverbal cues occurrences 
displayed by Addison, Laura, and Lucy, respectively. Focusing on proxemics, Addison Laura, and Lucy exhibited two visible behaviors (i.e., shifting seating positions and crossing arms) that occurred on three, seven, and two separate occasions, respectively, throughout the transcription. Proxemics was the least displayed nonverbal element.

Kinesics was distinctively apparent throughout the nonverbal analysis of the data. For Addison, Laura, and Lucy, six out of 13 nonverbal cues were related to kinesics. These behaviors were identified as: (a) "head nods," (b) "opened eyes widely," (c) "rolled eyes," (d) "subtle hand movement," (e) "squinted eyes," and (f) "waved hands." In addition to the notable amounts of nonverbal cues related to kinesics, the frequency with which each appears was significant. Calculating the frequencies of the 13 nonverbal cues for Addison, kinesics contributed to 43 out of 57 nonverbal cue occurrences. For Laura, 48 out of 79 nonverbal cue occurrences were accounted for by kinesics. For Lucy, 38 out of 48 nonverbal cue occurrences were accounted for by kinesics.

\section{Discussion}

Reviewing the findings from the domain, taxonomic, componential, and classical content analyses displayed the presence of challenges in role inequity and program perceptions. Addison's, Laura's, and Lucy's experiences throughout the doctoral process undoubtedly have been problematic. Like most doctoral students, the participants' challenges do not only surround intellectual difficulties, but also emotional difficulties (Stubb, Pyhältö, \& Lonka, 2011). This notion was exemplified by the results of this study.

Addison's, Laura's, and Lucy's realities were notably altered based on their experiences in the doctoral program. All facets of their lives (e.g., family life, personal life, or professional life) had to be re-evaluated in order to find balance and success in their educational aspirations. Although each participant discussed challenges due to her involvement in the doctoral program, they each expressed a strong connection, desire, and need to continue participation. Because of the mixed perceptions and role inequity caused by the doctoral program, effective strategies for coping and survival would be advantageous for each of the participants.

Caution should be practiced when reviewing the findings of this research study. The subject of the co-constructed questions utilized in this research focused primarily on the challenges encountered by doctoral students and possibly could have acted as a limitation to the study. Nunkoosing (2005) warned that interviewees often cater their responses to provide a warranted answer to the interviewer. It is possible that Addison, Laura, and Lucy focused primarily on challenging areas because the nature of the interview questions prompted this theme. Additionally, because the analyses (i.e., domain, taxonomic, and componential) used in this study required follow-up interviews, which would have provided the researcher with the opportunity to ask structural questions (i.e., derived from the domain and taxonomic analyses) and contrasting question (i.e., derived from the componential analysis), completed executions of the analyses were unachievable; possibly producing incomplete results. Added 
value could have been obtained from asking the structural and contrasting questions because these responses could have provided a more comprehensive understanding about Addison's, Laura's, and Lucy's life experiences.

Further, results from this collective case analysis should not be generalized to the doctoral student population. Evidence from this research is only applicable to Addison, Laura, and Lucy. To determine whether results are generalizable, more case studies must be completed. Extrapolation of the results from a greater amount of case studies would strengthen population validity (Onwuegbuzie, 2003).

\section{References}

Adler, P., \& Adler, P. (1987). Membership roles in field research. Newbury Park, CA: Sage.

Ali, A., \& Kohun, F. (2006). Dealing with isolation feelings in IS doctoral programs. International Journal of Doctoral Studies, 1, 21-33.

Barnes, B. J., \& Randall, J. (2012). Doctoral student satisfaction: An examination of disciplinary, enrollment, and institutional differences. Research in Higher Education, 53, 47-75. http://dx.doi.org/10.1007/s11162-011-9225-4

Biegel, D. E., Hokenstad, M. C., Singer, M. I., \& Guo, S. (2006). One school's experience in reconceptualizing part-time doctoral education in social work. Journal of Social Work Education, 42, 231-247. http://dx.doi.org/10.5175/JSWE.2006.200400454

Bowl, M. (2003). Non-traditional entrants to higher education: They talk about people like me. Stoke on Trent, England: Trentham.

Bronfenbrenner, U. (1979). The ecology of human development: Experiments by nature and design. Cambridge, MA: Harvard University Press.

Church, S. E. (2009). Facing reality: What are doctoral students' chances for success? Journal of Instructional Psychology, 36, 307-316.

Combs, J. P., \& Onwuegbuzie, A. J. (2012). Relationships among attitudes, coping strategies, and achievement in doctoral-level statistics courses: A mixed research study. International Journal of Doctoral Studies, 7, 349-375.

Constas, M. A. (1992). Qualitative analysis as a public event: The documentation of category development procedures. American Educational Research Journal, 29, 253-266. http://dx.doi.org/10.2307/1163368

Cooke, D. K., Sims, R. L., \& Peyrefitte, J. (1995). The relationship between graduate student attitudes and attrition. The Journal of Psychology, 129, 677-688. http://dx.doi.org/10.1080/00223980.1995.9914938

Council of Graduate Schools. (2008). Ph.D. completion and attrition: Analysis of baseline program data from the Ph.D. completion project. Washington, DC: Author.

Creswell, J. W. (2002). Educational research: Planning, conducting, and evaluating 
quantitative and qualitative research. Upper Saddle River, NJ: Pearson Education.

Creswell, J. W. (2005). Educational research: Planning, conducting, and evaluating quantitative and qualitative research (2nd ed.). Upper Saddle River, NJ: Pearson Education.

Curry, L. A., Nembhard, I. M., \& Bradley, E. H. (2009). Qualitative and mixed methods provide unique contributions to outcomes research. Circulation, 119, 1442-1452. http://dx.doi.org/10.1161/CIRCULATIONAHA.107.74277

De Valero, Y. F. (2001). Departmental factors affecting time-to-degree and completion rates of doctoral students at one land-grant research institution. The Journal of Higher Education, 72, 341-367. http://dx.doi.org/10.2307/2649335

Easter, M. M., Davis, A. M., \& Henderson, G. E. (2004). Confidentiality: More than a linkage file and a locked drawer. IRB: Ethics and Human Research, 26(2), 13-17. http://dx.doi.org/10.2307/3564233

Gardner, S. K. (2009). Student and faculty attributions of attrition in high and low-completing doctoral programs in the United States. Higher Education, 58, 97-112. http://dx.doi.org/10.1007/s10734-008-9184-7

Gardner, S. K. (2010). Contrasting the socialization experiences of doctoral students in high-and low-completing departments: A qualitative analysis of disciplinary contexts at one institution. The Journal of Higher Education, 81, 61-81.

Glaser, B. G., \& Strauss, A. L. (1967). The discovery of grounded theory: Strategies for qualitative research. Chicago, IL: Aldine.

Gold, J. M. (2006). Profiling marital satisfaction among graduate students: An analysis of the perceptions of masters and doctoral-students. Contemporary Family Therapy, 28, 485-495. http://dx.doi.org/10.1007/s10591-006-9019-6

Golde, C. M. (1998). Beginning graduate school: Explaining first-year doctoral attrition. New Directions for Higher Education, 1998, 55-64. http://dx.doi.org/10.1002/he.10105

Golde, C. M. (2005). The role of the department and discipline in doctoral student attrition: Lessons from four departments. The Journal of Higher Education, 76, 669-700. http://dx.doi.org/10.1353/jhe.2005.0039

Gorden, R. L. (1980). Interviewing: Strategy, techniques, and tactics. Homewood, IL: Dorsey.

Guba, E. G., \& Lincoln, Y. S. (1989). Fourth generation evaluation. Newbury Park, CA: Sage.

Herzig, A. H. (2002). Where have all the students gone? Participation of doctoral students in authentic mathematical activity as a necessary condition for persistence toward the PhD. Educational Studies in Mathematics, 50, 177-212.

Holsti, O. R. (1969). Content analysis for the social sciences and humanities. Reading, MA: Addison-Wesley. 
Hoskins, C. M., \& Goldberg, A. D. (2005). Doctoral student persistence in counselor education programs: Student-program match. Counselor Education and Supervision, 44, 175-188. http://dx.doi.org/10.1002/j.1556-6978.2005.tb01745.x

Hsieh, H. F., \& Shannon, S. E. (2005). Three approaches to qualitative content analysis. Qualitative Health Research, 15, 1277-1288. http://dx.doi.org/10.1177/1049732305276687

Iovacchini, E. V., Hall, L. M., \& Hengstler, D. D. (1985). Going back to college: Some differences between adult students and traditional students. College and University, 61, 43-54.

Ivankova, N. V., \& Stick, S. L. (2007). Students' persistence in a distributed doctoral program in educational leadership in higher education: A mixed methods study. $\begin{array}{llll}\text { Research in Higher Education, 48, } 35 . & \text { 93 }\end{array}$ http://dx.doi.org/10.1007/s11162-006-9025-4

Janesick, V. J. (2004). Stretching exercises for qualitative researchers (3rd ed.). Thousand Oaks, CA: Sage.

Krefting, L. (1991). Rigor in qualitative research: The assessment of trustworthiness. The American Journal of Occupational Therapy, 45, 214-222. http://dx.doi.org/10.5014/ajot.45.3.214

Kvale, S. (1996). Interviews: An introduction to qualitative research interviewing. London, England: Sage.

Leech, N. I., \& Onwuegbuzie, A. J. (2007). An array of qualitative data analysis tools: A call for data analysis triangulation. School Psychology Quarterly, 22, 557-584. http://dx.doi.org/10.1037/1045-380.22.4.557

Leech, N. I., \& Onwuegbuzie, A. J. (2008). Qualitative data analysis: A compendium of techniques and a framework for selection for school psychology research and beyond. School Psychology Quarterly, 23, 587-604. http://dx.doi.org/10.1037/1045-38030.23.4.587

Lincoln, Y. S., \& Guba, E. G. (1985). Naturalistic inquiry. Beverly Hills, CA: Sage.

Lovitts, B. E. (2001). Leaving the ivory tower: The causes and consequences of departure from doctoral study. Lanham, MD: Rowman \& Littlefield.

Manning, K. (1997). Authenticity in constructivist inquiry: Methodological considerations without prescription. Qualitative Inquiry, 3, 93-115. http://dx.doi.org/10.1177/107780049700300105

Martinez, E., Ordu, C., Della Sala, M. R., \& McFarlane, A. (2013). Striving to obtain a school-work-life balance: The full-time doctoral student. International Journal of Doctoral Studies, 8, 39-59.

Maxwell, J. A. (1992). Understanding and validity in qualitative research. In A. M. Huberman \& M. B. Miles (Eds.), The qualitative researcher's companion (pp. 37-64). 
Thousand Oaks, CA: Sage.

Merriam, S. (1998). Case study research in education: A qualitative Approach. San Francisco, CA: Jossey-Bass.

Miles, M. B., \& Huberman, A. M. (1994). Qualitative data analysis: A sourcebook of new methods. Beverly Hills, CA: Sage.

Nunkoosing, K. (2005). The problems with interviews. Qualitative Health Research, 15, 698-706. http://dx.doi.org/10.1177/1049732304273903

Onwuegbuzie, A. J. (2003). Expanding the framework of internal and external validity in quantitative research. Research in Schools, 10(1), 71-90.

Onwuegbuzie, A. J. (2012). Introduction: Putting the mixed back into quantitative and qualitative research in educational research and beyond: Moving towards the radical middle. International Journal of Multiple Research Approaches, 6, 192-219. http://dx.doi.org/10.5172/mra.2012.6.3.192

Onwuegbuzie, A. J., \& Byers, V. T. (2014). An exemplar for combining the collection, analysis, and interpretations of verbal and nonverbal data in qualitative research. International Journal of Education, 6, 183-246. http://dx.doi.org/10.5296/ije.v6i1.4399

Onwuegbuzie, A. J., \& Frels, R. K. (2013). Introduction: Towards a new research philosophy for addressing social justice issues: Critical dialectical pluralism 1.0. International $\begin{array}{lll}\text { Journal of Multiple Research Approaches, } & \text { 7, }\end{array}$ http://dx.doi.org/10.5172/mra.2013.7.1.9

Onwuegbuzie, A. J., \& Leech, N. L. (2007a). A call for qualitative power analyses. Quality \& Quantity: International Journal of Methodology, 41, 105-121. http://dx.doi.org/10.1007/s11135-005-1098-1

Onwuegbuzie, A. J., \& Leech, N. L. (2007b). Validity and qualitative research: An oxymoron? Quality \& Quantity: International Journal of Methodology, 41, 233-249. http://dx.doi.org/10.1007/s11135-006-9000-3

Onwuegbuzie, A. J., Leech, N. L., \& Collins, K. M. T. (2008). Interviewing the interpretive researcher: A method for addressing the crisis of representation, legitimation, and praxis. International Journal of Qualitative Methods, 7, 1-17.

Patton, M. Q. (1990). Qualitative evaluation and research methods (2nd ed.). Newbury Park, CA: Sage.

Pike, K. L. (1967). Language in relation to a unified theory of the structure of human behavior. The Hague, Netherlands: Mouton.

Provalis Research. (2011). QDA Miner (Version 4.0.3) [Computer software]. Montreal, Quebec, Canada: Author.

Rodwell, J., \& Neumann, R. (2008). Predictors of timely doctoral student completions by type of attendance: The utility of a pragmatic approach. Journal of Higher Education 
Policy and Management, 30, 65-76. http://dx.doi.org/10.1080/13600800701745069

Roulston, K. (2010). Considering quality in quantitative research. Qualitative Research, 10, 199-228. http://dx.doi.org/10.1177/1468794109356739

Schlemper, M. B. (2011). Challenges and coping in graduate school. The Geographical Bulletin, 52, 67-72.

Schoot, R. V., Yerkes, M. A., Mouw, J. M., \& Sonneveld, H. (2013). What took them so long? Explaining $\mathrm{PhD}$ delays among doctoral candidates. PLOS ONE, 8, 1-11. http://dx.doi.org/10.1371/journal.pone.0068839

Silverman, D. (2001). Interpreting qualitative data: Methods for analysing talk, text, and interaction (2nd ed.). London, England: Sage.

Spaulding, L. S., \& Rockinson-Szapkiw, A. J. (2012). Hearing their voices: Factors doctoral candidates attribute to their persistence. International Journal of Doctoral Studies, 7 , 199-219.

Spradley, J. P. (1979). The ethnographic interview. Cambridge, MA: International Thomson Publishing.

Stake, R. E. (2005). Qualitative case studies. In N. K. Denzin \& Y. S. Lincoln (Eds.), The Sage handbook of qualitative research (3rd ed., pp. 443-466). Thousand Oaks, CA: Sage.

Stubb, J., Pyhältö, K., \& Lonka, K. (2011). Balancing between inspiration and exhaustion: $\mathrm{PhD}$ students' experienced socio-psychological well-being. Studies in Continuing Education, 33, 33-50. http://dx.doi.org/10.1080/0158037X.2010.515572

Ülkü-Steiner, B., Kurtz-Costes, B., \& Kinlaw, C. R. (2000). Doctoral student experiences in gender-balanced and male-dominated graduate programs. Journal of Educational Psychology, 92, 296-307. http://dx.doi.org/10.1037/0022-0663.92.2.296

Wright, C. (1997). Gender matters: Access, welfare, teaching and learning. In D. McNamara \& R. Harris (Eds.), Overseas students in HE: Issues in teaching and learning (pp. 7690). London, England: Routledge.

Yin, R. K. (2004). The case study anthology. Thousand Oaks, CA: Sage.

\section{Copyright Disclaimer}

Copyright for this article is retained by the author(s), with first publication rights granted to the journal.

This is an open-access article distributed under the terms and conditions of the Creative Commons Attribution license (http://creativecommons.org/licenses/by/3.0/). 